Volume 5, Issue 1, February 2020, pp. 38-53

DOI: $10.23917 /$ jramathedu.v5i1.9703

p-ISSN: 2503-3697, e-ISSN: 2541-2590

\title{
Pre-service secondary teachers' knowledge of the function concept: A cluster analysis approach
}

\author{
José María Marbán*, Edgar John Sintema² \\ ${ }^{1}$ Department of Experimental, Social and Mathematical Sciences Teaching, University of Valladolid, Spain \\ ${ }^{2} \mathrm{PhD}$ candidate, School of Doctoral Studies, University of Valladolid, Spain \\ *Corresponding author: josemaria.marban@uva.es
}

\begin{tabular}{l} 
ARTICLE INFO \\
\hline Article history: \\
Received: 30 December 2020 \\
Revised: 16 February 2020 \\
Accepted: 18 February 2020 \\
Published online: 28 February \\
2020 \\
Published regularly: February \\
2020
\end{tabular}

Keywords:

Function concept, mathematics, pedagogical content knowledge, secondary teacher education, subjectmatter knowledge

\begin{abstract}
Teacher training is a key aspect for the success of any educational system and it is a prior challenge to face in-depth in Zambia. This study explores some dimensions of prospective secondary mathematics teachers' subject-matter knowledge and pedagogical content knowledge restricted to the topic of the function concept. Data were collected by means of a questionnaire that was administered to a sample of 150 prospective teachers enrolled at two public universities in Copperbelt, Zambia. A twostep cluster analysis was used to reveal natural grouping within the data set obtained. As a result, a two-cluster solution was revealed as the solution that best profiled the data, with participants within both clusters scoring low in the knowledge domains under consideration. To further understand the results a one-way between-subjects multivariate analysis of variance (MANOVA) and a follow-up discriminant function analysis (DFA) were also conducted. Common content knowledge was shown to be the most important factor in discriminating between prospective teachers in Cluster 1 and those in Cluster 2. The knowledge inadequacies identified are certainly worrisome and are likely to be transferred to young learners at secondary schools. Consequently, it is necessary to address with some urgency certain reforms in educational policies for teacher training programs in Zambia.
\end{abstract}

(C) 2020 Universitas Muhammadiyah Surakarta

\section{Introduction}

Ministry of General Education in Zambia views functional thinking as crucial for the development of mathematics literacy. This topic is included in the secondary school curriculum in Zambia as a key pre-requisite for learning calculus, equations solving and trigonometry, among other contents. Because functions can be expressed using different representations, secondary school students are accorded opportunities to use graphs in visualizing mathematical relationships that otherwise could be expressed using symbols. Functions also accord secondary school students' opportunities to model real-life situations and to understand relationships between phenomena in their environment. Thus, functions in the Zambian mathematics secondary school curriculum are taught early in the 10th grade to enable students to acquire important functional thinking skills fundamental for developing sound mathematical reasoning. However, the transition from

To cite this article:

Marbán, J. M., \& Sintema, E. J. (2020). Pre-service secondary teachers' knowledge of the function concept: A cluster analysis approach. JRAMathEdu (Journal of Research and Advances in Mathematics Education), 5(1), 38-53. doi:https://doi.org/10.23917/jramathedu.v5i1.9703 
the intended curriculum to the attained curriculum relies, to a great extent, on the quality of the implemented curriculum and this, in turn, on teacher training.

Research exclusively -or mainly-focusing on the mathematical knowledge that is necessary for teaching the concept of function has been on the increase in recent years (Aziz, Pramudiani, \& Purnomo, 2018; Aziz \& Kurniasih, 2019; Malambo, Van Putten, Botha, \& Stols, 2019; McCulloch, Lovett, \& Edgington, 2019; Lovett \& Edgington, 2019; Paoletti, Stevens, Hobson, Moore, \& LaForest, 2018; Sintema, Phiri, \&Marbán, 2018; Taşdan, 2019; Ubah \& Bansilal, 2018). In the paper by Aziz et al.(2018), the authors examined prospective secondary teachers' views regarding their knowledge of differences between functions and quadratic equations. Participants of that study exhibited deficiencies in ways in which they described and interpreted such differences. Later, Aziz and Kurniasih (2019) analyzed preservice secondary mathematics teachers' knowledge of representations of domain and range of functions. Results revealed a lack of understanding of both concepts and

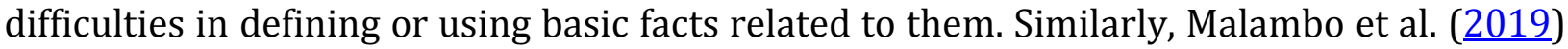
investigated pre-service mathematics teachers' understanding of secondary school level function concepts. By examining pre-service teachers' depth of knowledge related to the function concept, they argued that studying university level advanced mathematics was not a guarantee for comprehending school level function concepts. Their study revealed that most of the pre-service teachers who participated had problems justifying and explaining their reasoning of aspects of the function concept.

The studies conducted by McCulloch et al. (2019), on the one side, and Paoletti et al. ( $\underline{2018})$, on the other, we find two interesting and innovative approach to the teaching of functions. In the first of the papers mentioned, the authors used a vending machine applet to examine pre-service teachers' understanding of functions. Their findings indicated a renewed understanding of the definitions of the function concept for participants. In the second of the studies, the authors inquired about prospective teachers' knowledge about inverse function concepts with reference to techniques used and their meaning-making when learning the topic. The majority of participants in this study showed positive results in the tasks given.

In the particular context of Zambia, Sintema et al. (2018) conducted a literature review about Zambian mathematics prospective secondary teachers' knowledge of the function concept in which various issues related to its teaching were discussed. Recognizing students' difficulties, misconceptions and erroneous reasoning related to the function concept, they argued that teaching different representations of functions were among the most challenging tasks facing teachers. They also emphasized the need for teachers to clearly teach the meaning of symbols that are used to teach functions. This fact was also observed in a case study developed by (Sajka, 2003) who observed that the participant exhibited limited understanding of the function concept by misinterpreting symbols used when learning functional equations which were intrinsically caused by context that restricted the use of symbols during teaching and the kind of examples and tasks teachers selected for their students.

Tasdan (2019) studied how teachers used explanations, descriptions, and justifications of function concepts during classroom interactions with secondary school students. They argued that correct explanations, descriptions, and justifications of concepts were crucial for teachers to effectively teach function because it had implications for student comprehension of the concepts. Results revealed gaps in teachers' knowledge in the context of the function concept.

In the last of these studies mentioned above, the one conducted by Ubah and Bansilal (2018), the authors investigated prospective mathematics teachers' knowledge of 
quadratic functions. Their focus was on exploring approaches teachers employed when deriving symbolic equations for graphs of quadratic equations and how they did this in a variety of ways. Findings indicated that participants showed unpreparedness to effectively teach school level concepts and recommended more pedagogical skills.

Other recent studies focusing on teacher's mathematical knowledge of functions are the one conducted by Hatisaru and Erbas (2017), where the interrelationship between such knowledge and students' outcomes is analyzed, and the work of Steele, Hillen, and Smith (2013), who conducted a study to examine in-service and pre-service teachers' knowledge development for teaching the function concept. Results in this latter case indicated a positive growth of teacher's knowledge concerning the definition of the function concept together with the selection of appropriate examples.

Beyond the focus on mathematical content shared by the papers previously mentioned, we find Even (1993) which, according to our opinion, stands out as one of the most extensive studies about pre-service teachers' subject-matter and pedagogical content knowledge of the concept of a function. Even studied the interrelations between both types of knowledge in 152 pre-service secondary teachers finding out that participants had limited knowledge of the function concept which affected their pedagogical content knowledge. More recently, Nyikahadzoyi (2015) studied teachers' knowledge of the function concept by using a teaching framework inspired by the works of Shulman (1986)

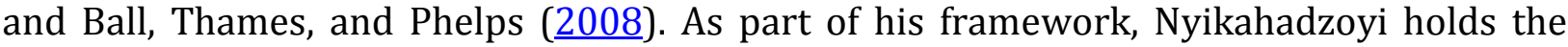
view that teachers' knowledge of students and the function concept is premised on teachers' knowledge of student misconceptions, errors, and difficulties, together with teacher's ability to anticipate content that will motivate their students and that might likely to be challenging for them. Closely connected we find the work by Aksu and Kul (2016) who investigated in-service teachers' knowledge of content and students in the sense of the Mathematical Knowledge for Teaching framework established by Ball et al. (2008). Their study particularly focused on teachers' knowledge of student errors, misconceptions, and difficulties while learning functions in secondary school. Results of the study revealed deficiencies in teachers' knowledge of their learners' difficulties, errors and misconceptions.

Other interesting works are the one by Hatisaru and Erbas (2017), Taşdan and

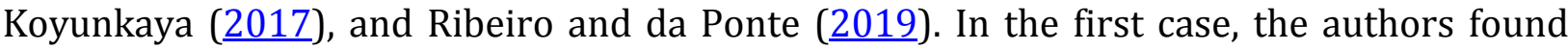
some relationship between teachers' MKT and the learning outcomes of their students. The study also indicated that the quality of teachers' pedagogical practices was influenced by their knowledge of the concept. In their study of prospective secondary teachers' knowledge of functions, Taşdan and Koyunkaya (2017) found that there existed a relationship between experience and how the teacher taught the function concept. A relationship was also found between experience and teachers' classroom management as well as teachers' effective interaction with students. Finally, Ribeiro and da Ponte (2019) assessed the identity of in-service teachers' professional learning opportunities related to the didactical and mathematical knowledge of the function concept. Findings revealed professional learning support for mathematical knowledge of different aspects of functions that included representation of functions using tables and algebraic form.

Research on pre-service teachers' knowledge of the concept of function, on the one hand, and how their corresponding subject-matter knowledge and their knowledge of content and students interrelate to achieve effective learning goals, on the other hand, is still in its infancy in Zambia, as it is also the case in many other similar international educational contexts. Thus, this study aims to contribute to shedding light on both issues. Besides, being a study developed within the national context of Zambia, it has drawn its 
inspiration from the exploratory study by Malambo ( $\underline{2016})$ about student teachers' content knowledge of functions and trigonometry. However, the current study is concerned with both subject-matter and pedagogical content knowledge as complementary and key aspects to effectively teach functions in mathematics classrooms.

\section{Theoretical framework}

Based on the notion of Pedagogical Content Knowledge (PCK) introduced by Shulman (1986), researchers at the University of Michigan collaborated to re-conceptualize it and to develop what came to be known as the Mathematical Knowledge for Teaching (MKT) framework (Ball et al., 2008; Thames \& Ball, 2010). The MKT framework comprised two major knowledge domains (Figure 1) namely subject matter knowledge and pedagogical content knowledge, each of them with three sub-domains: common content knowledge (CCK), specialized content knowledge (SCK) and horizon content knowledge (HCK) in the first case and knowledge of content and students (KCS), knowledge of content and teaching (KCT) and knowledge of content and curriculum (KCC) in the second.

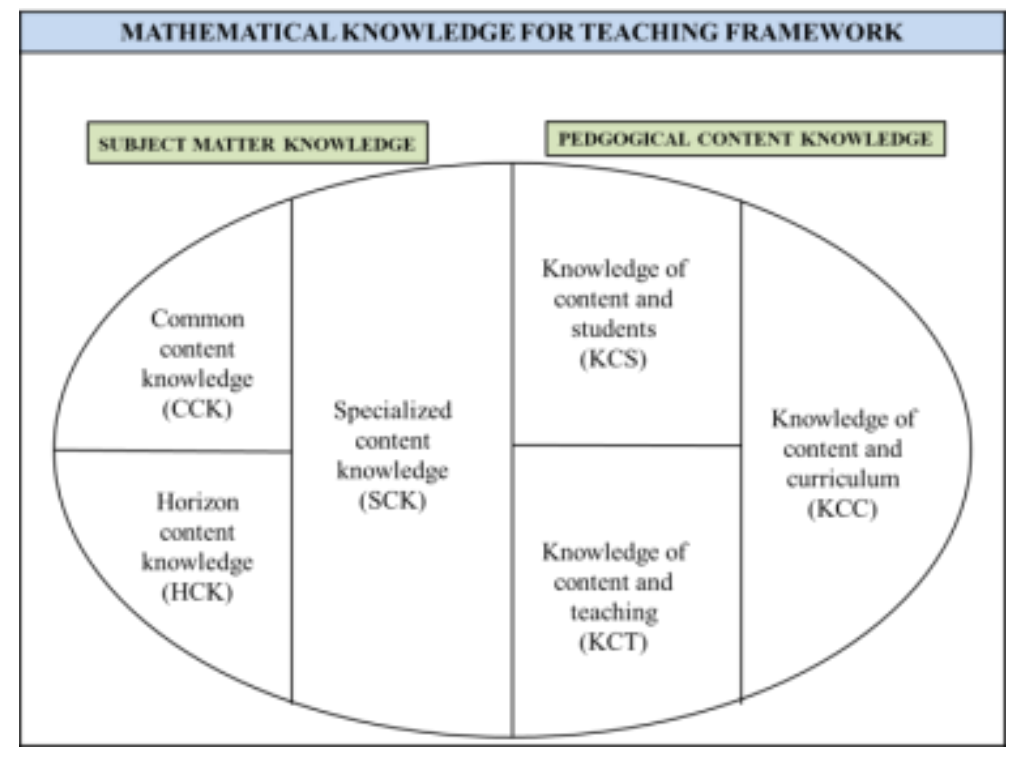

Figure 1. Mathematical knowledge for teaching (Ball et al., 2008)

The MKT framework became popular in mathematics education studies around the world as scholars started using the framework to study different aspects of mathematics education and, in particular, mathematical knowledge for teaching the concept of a function (Nyikahadzoyi, 2015; Steele et al., 2013). Based on the works by Ball et al. (2008),

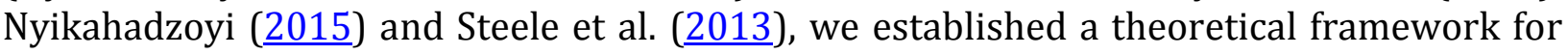
this study (Figure 2) in order to ensure an explicit definition of the key aspects of the MKT that are referred to in this study.

According to this framework, pre-service teachers' knowledge of the concept of a function was composed of their knowledge of subject-matter and their pedagogical content knowledge. For this study subject-matter knowledge was limited to common content knowledge and specialized content knowledge of the function concept. Pedagogical content knowledge, on the other hand, was limited to knowledge of function concept content and students. 


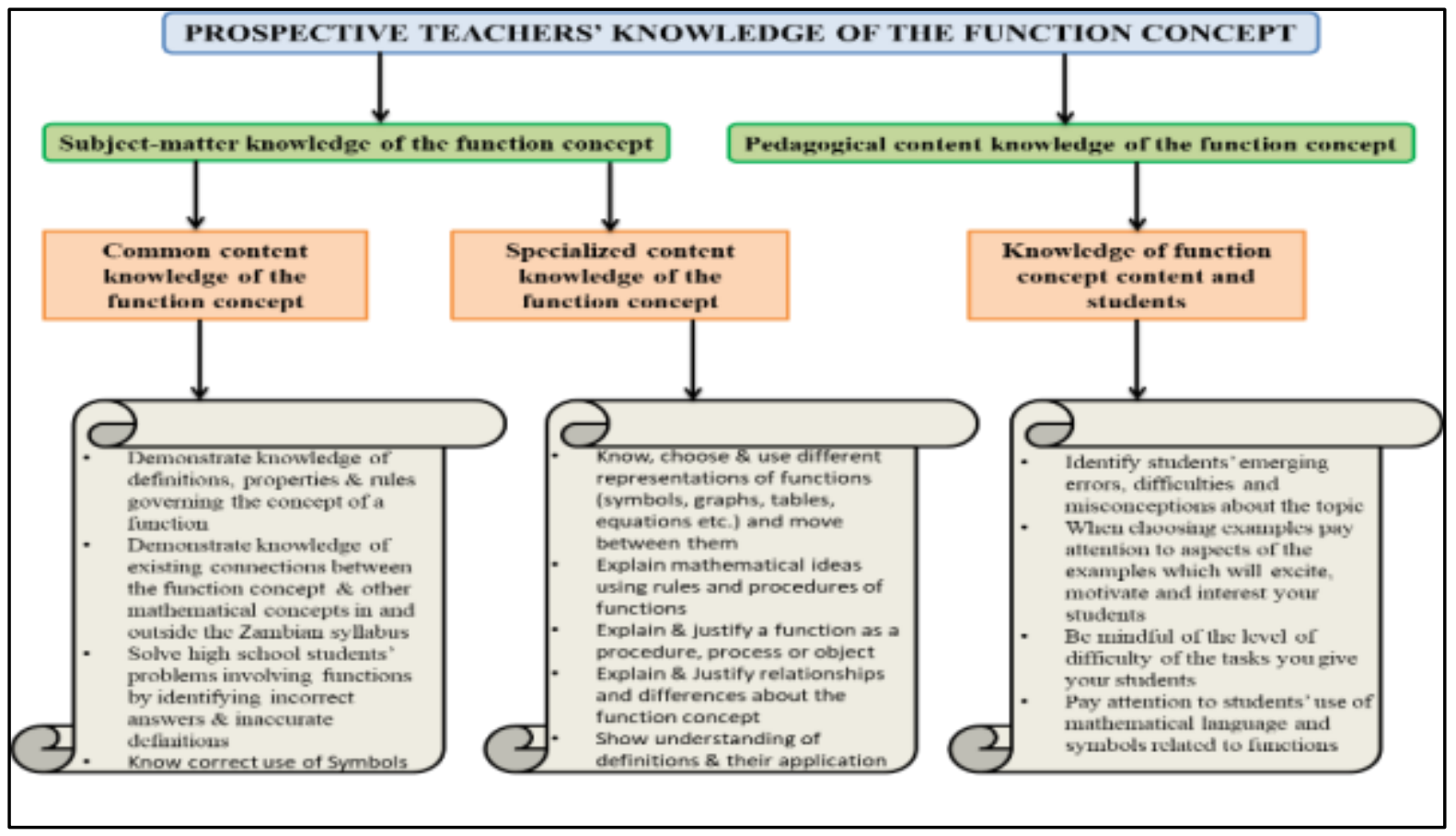

Figure 2. Teaching framework for prospective mathematics teachers' knowledge of the function concept

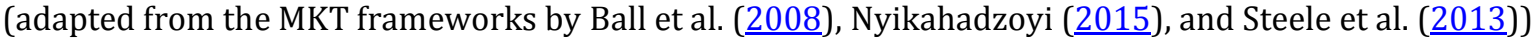

Common content knowledge of the function concept was defined as the teacher's ability to demonstrate knowledge of the definition of the function concept including knowledge of the properties and rules that govern the function concept. The teacher also needs to demonstrate knowledge of existing connections between the function concept and other mathematical concepts in the Zambian secondary school syllabus. The teacher further needs to demonstrate his/her ability to solve high school students' problems involving functions by identifying correct and incorrect answers and inaccurate definitions as provided for in the mathematics textbooks and other curriculum materials recommended by the Zambia Ministry of General Education. The teacher also needs to show mastery and knowledge of correct use of symbols related to the function concept and be able to show the students examples and nom examples of function.

Specialized content knowledge of the function concept was defined as the teacher's ability to demonstrate knowledge of how to use a different representation of function (symbols, graphs, tables, equations, etc.) and his/her flexibility in moving between them during classroom instruction. The teacher is also supposed to use his/her knowledge of properties, rules, and procedures governing the function concept to explain mathematical ideas related to real-life applications of the concept. The teacher should be able to show understanding of definitions of functions and their applications to a variety of situations. $\mathrm{He} /$ she must be able to explicitly explain and justify existing relationships and differences between function concepts by demonstrating that functions can be understood as a procedure, process or object.

Knowledge of function concept content and students was defined as the teacher's ability to anticipate and identify students' emerging errors, difficulties, and misconceptions related to the function concept. The teacher needs to choose examples which would excite motivate and interest students and be mindful of the level of difficulty of the tasks given to students as class work and homework. The teacher needs to pay particular attention to 
students' use of mathematical language and symbols related to the function concept. This is because the correct use of language and symbols enhances comprehension of concepts.

\section{Research Methods}

This study is part of a larger ongoing project that employed a sequential explanatory mixed-method approach as it offers a "more complete picture and an in-depth understanding of the research question than either quantitative or qualitative approaches" (Creswell, 2014). However, the results reported in this study are just a part of the quantitative analysis that was performed. The complete set of quantitative analysis together with the qualitative results has been left out and will be published at the end of the project mentioned above.

As has just been mentioned, a quantitative approach for this study (see Figure 3) was chosen based on the overall design employed in the project. One of the questions this quantitative phase sought to answer was that concerning the level of proficiency Zambian prospective mathematics secondary teachers' exhibit when asked about the function concept, on the one hand, and about errors, misconceptions and difficulties secondary students show when working with functions, on the other side. Besides, this quantitative approach sought also to explore interrelations between both types of knowledge.

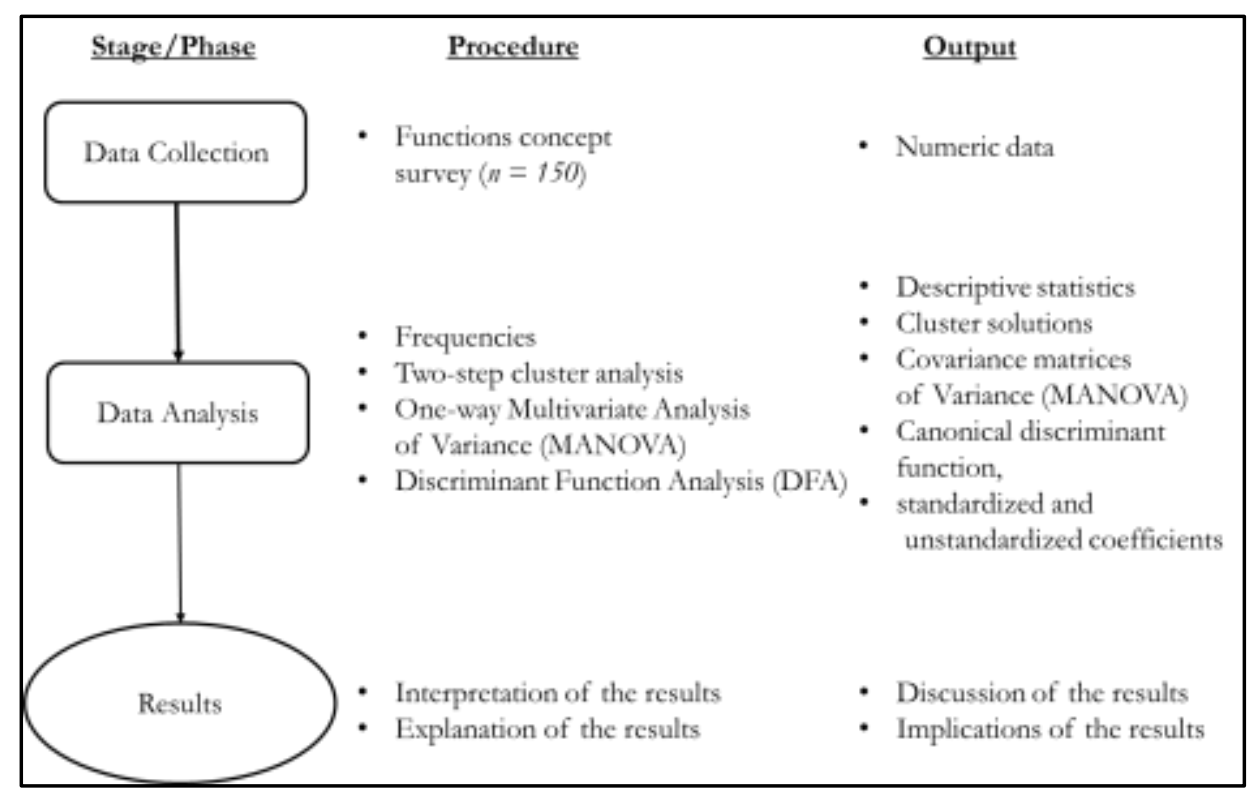

Figure 3. Visual representation of the quantitative design procedure for this study (adapted from Creswell, 2014)

\section{Participants}

Participants of this study were 150 third- and fourth-year mathematics education students from two public universities located on the Copperbelt province of Zambia. Participants possessed similar characteristics and both universities had covered, in terms of taught curriculum, the concept of a function to a level satisfactory enough for their students to participate in this study. All the participants attended secondary school in Zambia and had a good orientation of the Zambian secondary school mathematics curriculum. It was important for the participants to be accustomed to the mathematics secondary school curriculum because this study is based on their ability to teach functions in Zambian secondary school when they leave university. 


\section{Instruments}

The project from which results of this study were extracted used more than two instruments to examine prospective mathematics secondary teachers' subject matter and pedagogical content knowledge. In this study, we showcase the results of a survey on functions in the form of a pencil and paper test administered to the participants. The instrument was first developed using a combination of selected items previously used in other studies (Even, 1990, 1993; Malambo, 2016; Watson, Ayalon, \& Lerman, 2018; You, $\underline{2010}$ ) and then went through a complete process of validation before being used to collect data for this study. Items in the survey covered three domains of the MKT framework (Ball et al., 2008) namely common content knowledge (CCK), specialized content knowledge (SCK) and knowledge of content and students (KCS). The three knowledge domains are the focus of the project from which this study emanates. The survey consisted of35 items distributes in 9 questions.

\section{Data analysis}

Data for this study were analyzed using SPSS 23. A two-step cluster analysis procedure was employed to categorize participants into groups based on the CCK, SCK, and KCS. This technique was chosen due to its potential effectiveness in the context of this study to group participants from their knowledge features provided by data from the survey. We also computed descriptive statistics for each cluster and performed a one-way multivariate analysis of variance (MANOVA) to compare participants' knowledge between the two clusters together with a follow-up discriminant function analysis (DFA).

\section{Results and Discussion}

As a first result, the two-step auto clustering analysis revealed a two-cluster solution as the one that best profiled the data (Table 1). The predictor importance of knowledge dimensions to the formation of the clusters was $\mathrm{SCK}=1.74, \mathrm{CCK}=1.00$ and $\mathrm{KCS}=0.77$, respectively and the ratio of a large cluster to a small cluster was 1.08 ,a value that can be considered as good.

Table 1

Results of the auto-clustering for the two-step cluster analysis

\begin{tabular}{ccccc}
\hline Cluster & $\begin{array}{c}\text { Schwarz's } \\
\text { Bayesian Criterion } \\
\text { (BIC) }\end{array}$ & BIC Change & $\begin{array}{c}\text { Ratio of BIC } \\
\text { Changes }^{\mathrm{b}}\end{array}$ & $\begin{array}{c}\text { Ratio of } \\
\text { Distance }_{\text {Measures }^{\mathrm{c}}}\end{array}$ \\
\hline 1 & 788.97 & -118.97 & 1.000 & 2.39 \\
2 & 785.65 & -3.32 & .03 & 1.79 \\
\hline
\end{tabular}

a. The changes are from the previous number of clusters in the table.

b. The ratios of changes are relative to the change for the two-cluster solution.

c. The ratios of distance measures are based on the current number of clusters against the previous number of clusters.

Table 2 shows the overall performance of prospective teachers over a maximum of 100 marks according to their answers to the questions comprising the questionnaire used in this study. Examining the results, we see that 91 out of the 150 participants failed to reach the pass mark (61 from Cluster 1 and 30 from Cluster 2) while only a total of 12 participants ( 1 from Cluster 1 and 11 from Cluster 2) scored between 70 and 79 marks, 
which represented a good performance, and just 5 prospective teachers scored at least 80 marks (all of them belonging to Cluster 2).

Table 2

Final results of pre-service teachers' performance in the functions concept survey

\begin{tabular}{lccc}
\hline Classification & Cluster 1 & Cluster 2 & Total \\
\hline Fail (0-49) & 61 & 30 & $\mathbf{9 1}$ \\
Fair (50-69) & 9 & 33 & $\mathbf{4 2}$ \\
Good (70-79) & 1 & 11 & $\mathbf{1 2}$ \\
Very Good (80-100) & 0 & 5 & $\mathbf{5}$ \\
Total & $\mathbf{7 1}$ & $\mathbf{7 9}$ & $\mathbf{1 5 0}$ \\
\hline
\end{tabular}

Table 3 allows us to look at the average performance (always in a scale 0-100 and with the corresponding standard deviations into brackets) of prospective teachers across the two clusters. Although it can be seen that prospective teachers in Cluster 2 performed better than their counterparts in Cluster 1, general performance was very low in CCK, SCK, and KCS with the best performance of 23.13 in average in CCK posted by participants in Cluster 2 and the least being 11.93 in KCS from Cluster 1 in this case.

Table 3

Performance profiles of pre-service mathematics teachers by cluster for each knowledge dimension

\begin{tabular}{cccccc}
\hline Cluster & Cluster size & $\begin{array}{c}\text { Overall } \\
\text { (35 items) }\end{array}$ & $\begin{array}{c}\text { Common } \\
\text { content } \\
\text { knowledge } \\
\text { (15 items) }\end{array}$ & $\begin{array}{c}\text { Specialized } \\
\text { content } \\
\text { knowledge } \\
\text { (13 items) }\end{array}$ & $\begin{array}{c}\text { Knowledge of } \\
\text { content and } \\
\text { students } \\
\text { (7 items) }\end{array}$ \\
\hline 1 & $72(48 \%)$ & $12.94(3.72)$ & $14.93(3.82)$ & $11.96(3.63)$ & $11.93(3.71)$ \\
2 & $78(52 \%)$ & $19.11(4.60)$ & $23.13(5.64)$ & $17.56(4.38)$ & $16.65(3.80)$ \\
\hline
\end{tabular}

This difference between clusters can also be better observed when looking at the Mboxes collected in Figure 4.

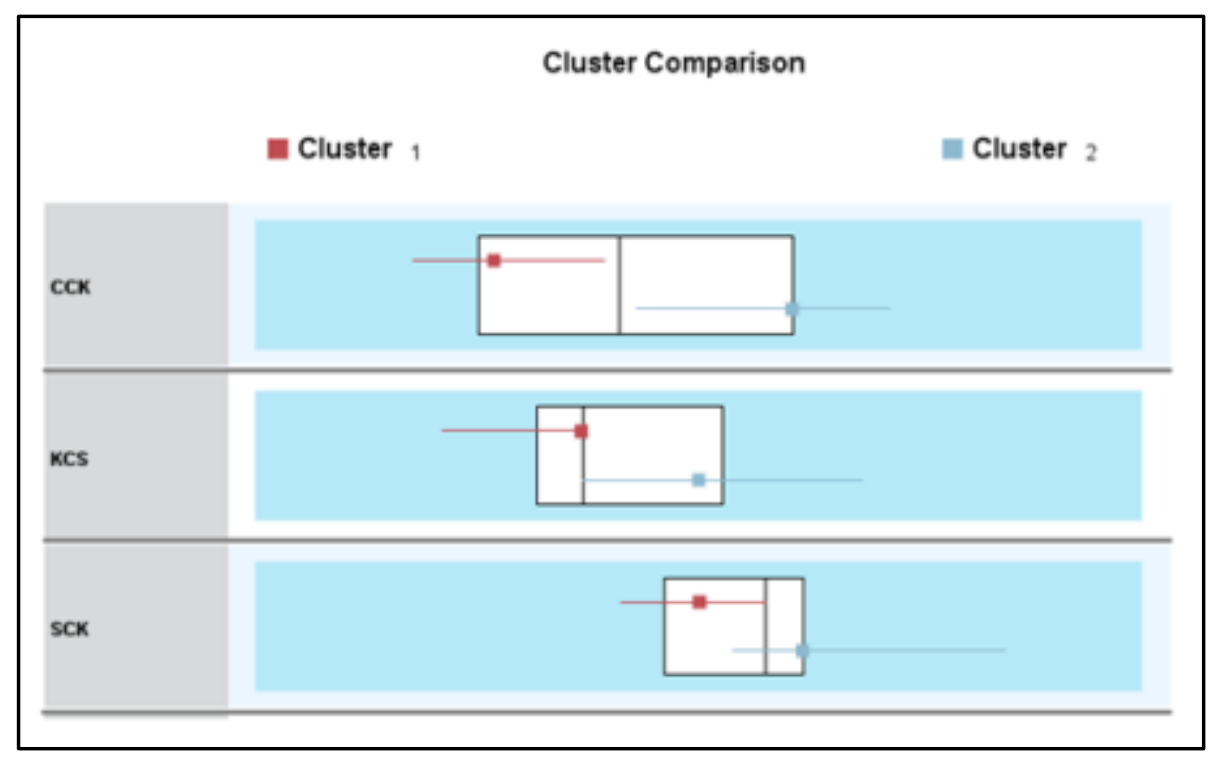

Figure 4. Cluster comparison of prospective mathematics secondary teachers' performance 
Table 4 shows the minimum and maximum scores for each knowledge domain by the cluster. The minimum CCK score was 7(Cluster 1) while the maximum CCK score was 35 (Cluster 2). As for SCK, Cluster 1 posted the minimum score of 0 while 26 was the maximum score for Cluster 2. The minimum KCS score was 6 (Cluster 1) while the maximum KCS score was 25 (Cluster 2).

Table 4

Knowledge profiles of prospective Zambian mathematics teachers based on their CCK, SCK, and KCS

\begin{tabular}{ccccccccc}
\hline \multirow{2}{*}{ Dimension } & \multicolumn{2}{c}{ Mean } & \multicolumn{2}{c}{ Minimum } & \multicolumn{2}{c}{ Maximum } & \multicolumn{2}{c}{ Std } \\
\cline { 2 - 8 } & Cluster 1 & Cluster 2 & Cluster 1 & Cluster 2 & Cluster 1 & Cluster 2 & Cluster 1 & Cluster 2 \\
\hline CCK & 14.83 & 23.14 & 7 & 12 & 24 & 35 & 3.75 & 5.64 \\
SCK & 11.90 & 17.56 & 0 & 11 & 18 & 26 & 3.62 & 4.38 \\
KCS & 11.85 & 16.65 & 6 & 11 & 18 & 25 & 2.63 & 3.80 \\
\hline
\end{tabular}

Based on the theoretical framework for this study (see Figure 1), common content knowledge, specialized content knowledge and knowledge of content and students were further analyzed to give an in-depth picture of prospective teachers' knowledge. This was done because the framework reflected CCK and SCK as characteristics that were a major focus in the Zambia mathematics curriculum.

Thus, CCK was further analyzed in terms of teacher's knowledge about definitions of relations and functions (KDRF), calculations involving inverse, quadratic and composite functions (CIQCF) and teacher's knowledge about the appropriate selection of examples and non-examples of relations and functions (KASERF). Cluster 2 prospective teachers performed better than those in Cluster 1 in terms of KDRF, CIQCF, and KASERF (Table 5). A maximum score of 19 (CIQCF) and a minimum score of 1 (KASERF) were recorded for Cluster 2 and Cluster 1 respectively.

Table 5

Performance profiles of prospective mathematics teachers by cluster for the constructs of knowledge domains

\begin{tabular}{|c|c|c|c|c|c|c|c|c|}
\hline \multirow[b]{2}{*}{ Sub-Dimension } & \multicolumn{2}{|c|}{ Mean } & \multicolumn{2}{|c|}{ Minimum } & \multicolumn{2}{|c|}{ Maximum } & \multicolumn{2}{|c|}{ Std } \\
\hline & $\begin{array}{c}\text { Cluster } \\
1 \\
\end{array}$ & $\begin{array}{c}\text { Cluster } \\
2 \\
\end{array}$ & $\begin{array}{c}\text { Cluster } \\
1 \\
\end{array}$ & $\begin{array}{c}\text { Cluster } \\
2 \\
\end{array}$ & $\begin{array}{c}\text { Cluster } \\
1 \\
\end{array}$ & $\begin{array}{c}\text { Cluster } \\
2 \\
\end{array}$ & $\begin{array}{c}\text { Cluster } \\
1 \\
\end{array}$ & $\begin{array}{c}\text { Cluster } \\
2 \\
\end{array}$ \\
\hline KDRF & 5.66 & 7.15 & 2 & 4 & 8 & 10 & 1.79 & 1.32 \\
\hline KASERF & 2.38 & 3.55 & 1 & 2 & 4 & 6 & .88 & 1.16 \\
\hline CIQCF & 6.79 & 12.44 & 4 & 5 & 13 & 19 & 1.68 & 4.29 \\
\hline EJRDRF & 3.65 & 4.15 & 0 & 2 & 6 & 6 & 0.93 & 1.01 \\
\hline EJEF & 1.10 & 2.26 & 0 & 0 & 3 & 5 & .45 & 1.38 \\
\hline EJRRDF & 1.65 & 3.56 & 0 & 0 & 4 & 6 & 1.27 & 1.31 \\
\hline KDRRF & 6.65 & 10.65 & 0 & 4 & 10 & 17 & 2.26 & 3.72 \\
\hline KSDME & 11.85 & 16.65 & 6 & 11 & 18 & 25 & 2.63 & 3.80 \\
\hline
\end{tabular}

It can be seen from the foregoing that the level of CCK proficiency for prospective teachers in Cluster 1 was lower than that of their counterparts in Cluster 2. This implies that pre-service teachers in Cluster 1 are more likely to exhibit low knowledge levels in the definition of concepts related to functions. They are also less likely to exhibit real and good challenges in the use and explanation of mathematical symbols and in the selection of examples and non-examples of functions. Such gaps in knowledge are a worrying fact that might be easily transferred to their future secondary school students

SCK was analyzed in terms of the ability of participants to manage with different representations of relations and functions (KDRRF), explanations and justifications of 
relationships between the ranges and domains of functions (EJRRDF), explanation and justification of examples and non-examples of functions (EJEF) and explanations and justification of relationships and differences between relations and functions (EJRDRF). Both Cluster 1 and Cluster 2 recorded a minimum score of 0 in EJEF and EJRRDF (Table 5) while 17was the maximum for all the four sub-dimensions of SCK, attained for KDRRF. KCS was also further analyzed in terms of knowledge of students' difficulties, misconceptions, and errors (KSDME). The maximum KSDME score was 25 while the minimum was 6.

Based once more on the framework described in Figure 1, it can be argued that both clusters were composed of participants who had troubles when dealing with the explanation and justification of examples of functions and when explaining and justifying relationships between ranges and domains of functions. To avoid transferring these knowledge gaps to secondary school students, prospective teachers need to improve their EJEF and EJRRDF. Also, teachers need to improve their KSDME as part of their KSC. Low KSC implies difficulties in anticipating and resolving secondary school students' misconceptions and errors as well as in selecting good and challenging examples that motivate the students to learn.

Though content analysis of the answers provided by participants from both clusters is far beyond the scope of this paper, the following examples might help to understand much better what is behind some of the global figures provided in the tables.

The first example is related to specialized content knowledge and how prospective teachers are expected to work with different representations of functions. The question in Figure 5, which was extracted from the survey used for data collection in this study, was aimed at assessing the level of knowledge of analyzing graphs of quadratic functions. The key features that they were expected to bring out when analyzing the given graphs included (but were not limited to) using the general form $f(x)=a x^{2}+b x+c$ where $a, b$ and $\mathrm{c}$ are constants and $\mathrm{a} \neq 0, \mathrm{x}$ and $\mathrm{y}$ intercepts of the graph, stationary (minimum and maximum) points, axes of symmetry and the nature of roots of the quadratic functions. For this purpose, excerpts from two students are presented in this paper to show how the two participants analyzed the graphs.

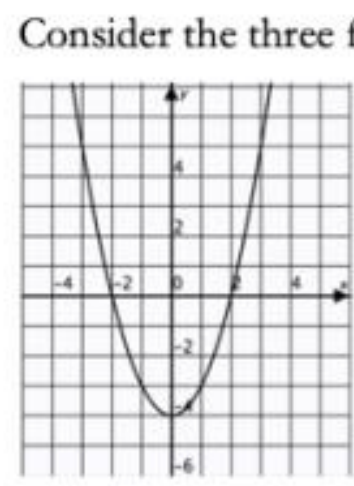

Figure A

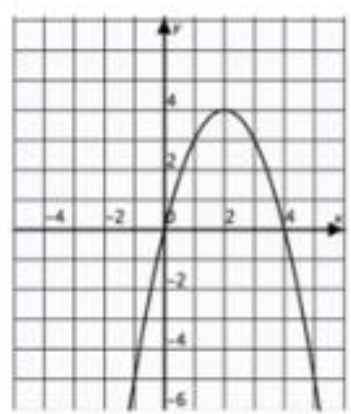

Figure B

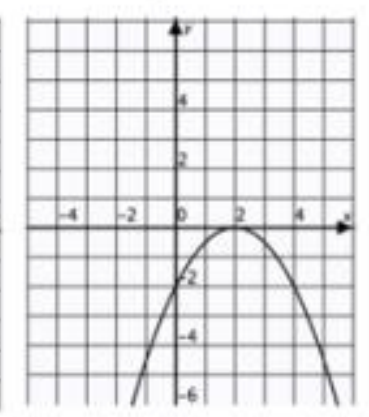

Figure C

(a) Indicate the features that are common to graphs A and B but not to graph C.

(b) Indicate the features that are common to graphs B and C but not to graph A.

(c) Indicate the features that are common to graphs $\mathrm{A}$ and $\mathrm{C}$ but not to graph $\mathrm{B}$.

Figure 5. Statement of a question about graphs of quadratic functions. 
The first participant was able to distinguish figures $A, B$ and $C$ in terms of the nature of roots and the x-intercepts (Figure 6). The participant observed that in Figures A and B there exist distinct roots because the graphs intersect the $\mathrm{x}$-axis at two distinct points, while the graph of the function in Figure $C$ intersects the $\mathrm{x}$-axis at only one point. The participant also observed that a major difference between graphs of quadratic functions in Figures $\mathrm{B}$ and $\mathrm{C}$ is that they have maximum turning points while the graph in Figure $\mathrm{A}$ has a minimum turning point.

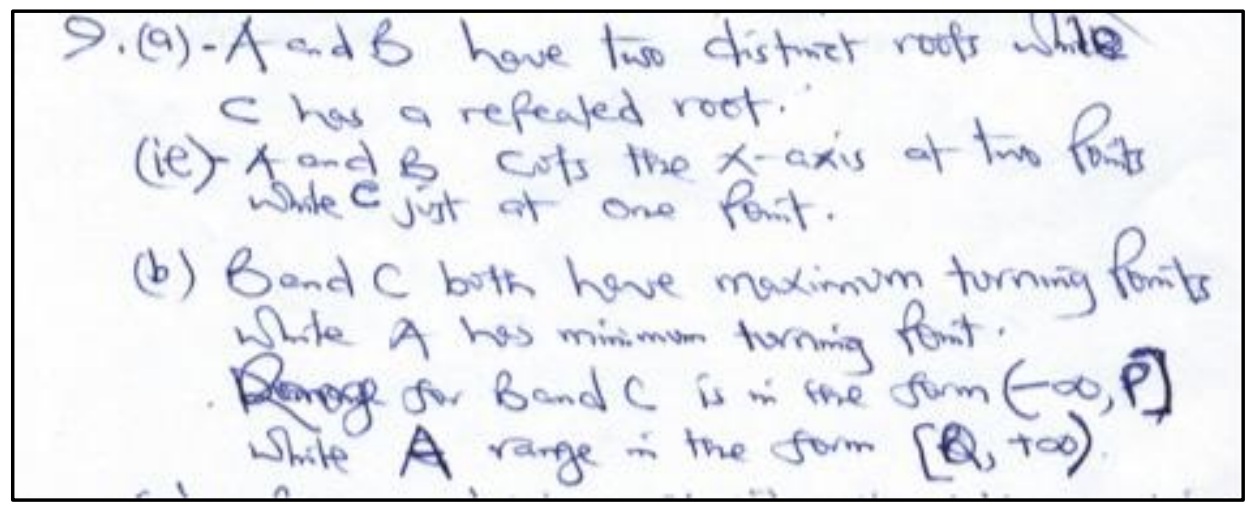

Figure 6. Excerpt from the answer of participant 1.

However, he could not explain why in figure A the parabola opens upwards while in the other two figures the parabolas open downwards and possibly relate this to the coefficient of $\mathrm{x}^{2}$ in the general form $\mathrm{f}(\mathrm{x})=\mathrm{ax}^{2}+\mathrm{bx}+\mathrm{c}$. It can be seen from the explanations advanced by this participant that there are gaps in his specialized content knowledge as he was not thoroughly able to work with different representations.

The second participant brought out different aspects of the distinction between graphs. In part (a) he concentrated more of the $\mathrm{x}$-intercepts and to some extent, on the symmetry of the graphs in figures A and B. It might have been good for this participant to talk also about the nature of the root as his mere mention of the roots was not enough to explain the difference. In part (b) the participant stated the axis of symmetry of the graphs in figures B and C. Symmetry in this situation was one of the key features that would help draw a distinction. The first student did not state the axis of symmetry which was a major omission from his explanations. For the second student, it was also important to state the nature of the turning point of the given graphs which was omitted. In part (c) the participant stated the x-intercept as the major difference. He could also have talked about the $y$-intercept which the first student talked about.

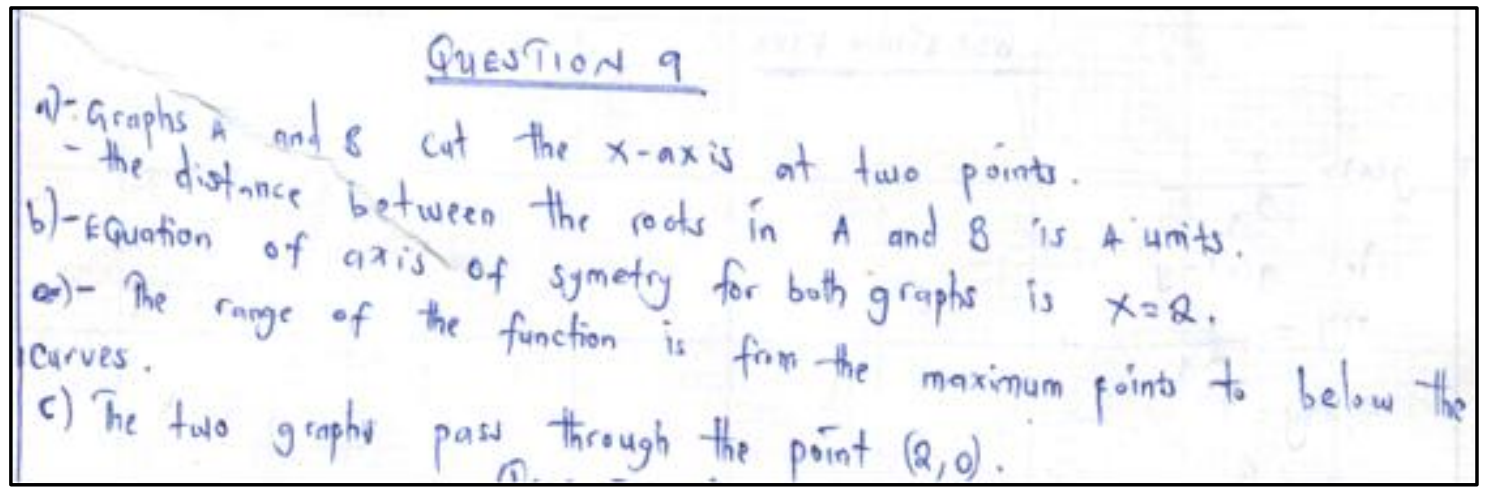

Figure 7. Excerpt from the answer of participant 2. 
The second example concerns a question of the survey that was meant to assess preservice teachers' knowledge of the concept of the function content and students (Figure 8).

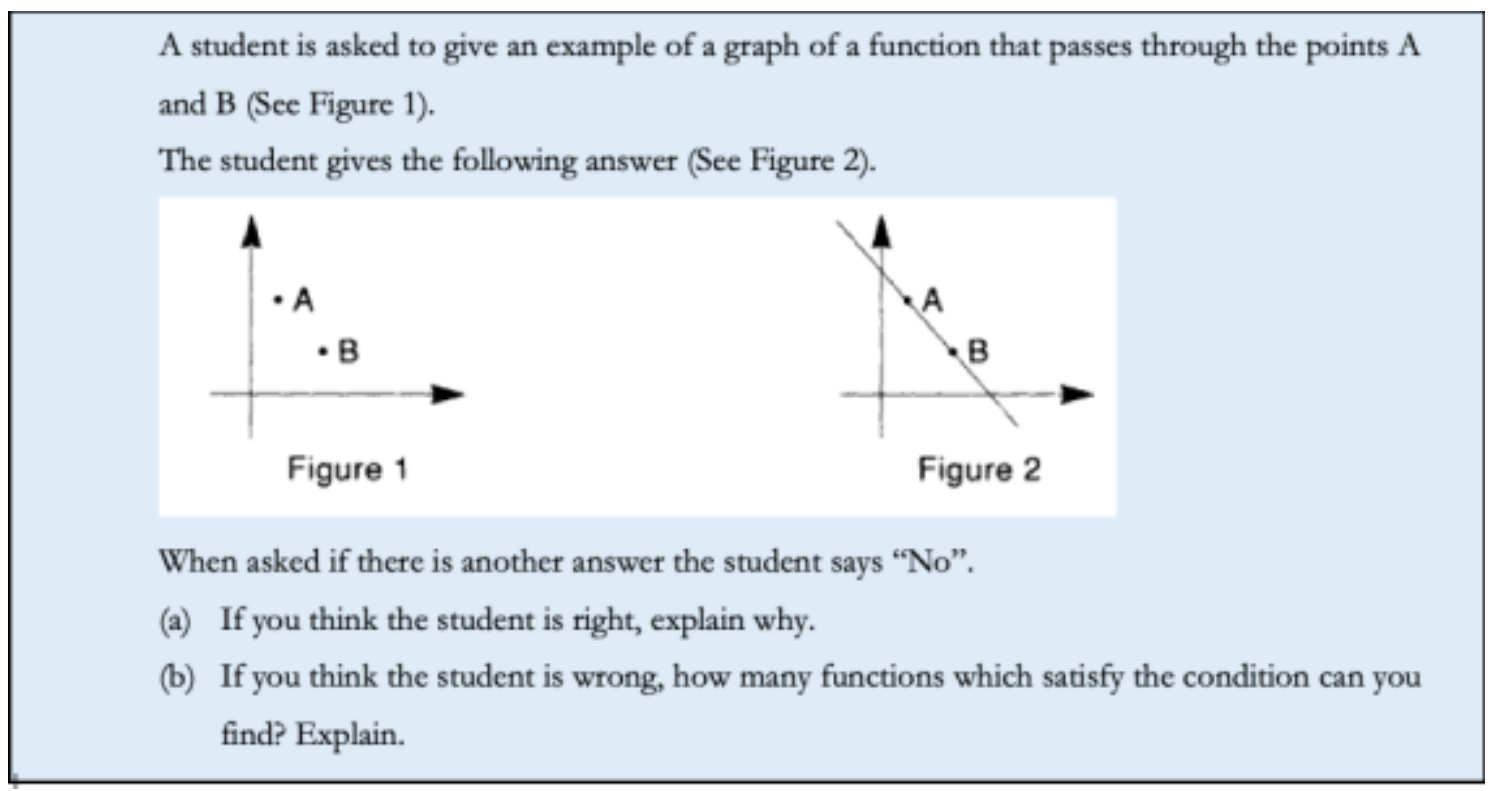

Figure 8. Statement of a question about interpreting students' answers

A participant from Cluster 2 provided the answer shown below (Figure 9)exhibiting a strong knowledge of the issue addressed in the question.

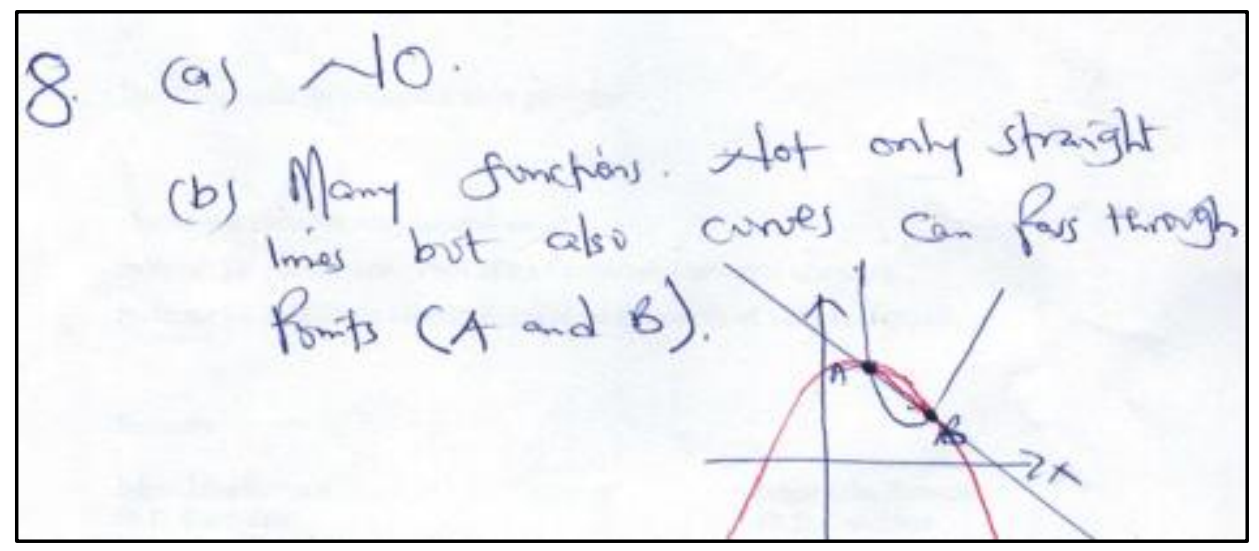

Figure 9. Answer to question in Figure 8 provided by a participant from Cluster 2.

To further understand prospective teachers' knowledge of the function concept, we conducted a one-way between-subjects multivariate analysis of variance (MANOVA) and a follow-up discriminant function analysis (DFA). In the MANOVA test, the clusters derived from the two-step cluster analysis procedure formed the independent variable while the three MKT knowledge domains (CCK, SCK, and KCS) were the dependent variables. The .05 level of significance was set a priori for the analysis. Comparison of the prospective teachers' performance in the CCK, SCK and KCS knowledge domains across the clusters signified their knowledge of the function concept.

Table 6 shows the univariate analysis results of prospective secondary mathematics teachers' performance across all the three knowledge domains CCK, SCK, and KCS in each cluster. As can be seen, there was a statistically significant difference in the prospective teachers' CCK, SCK, and KCS of the function concept. 
Table 6

Between levels of cluster effects of prospective secondary mathematics teachers' knowledge of the function concept

\begin{tabular}{ccccccc}
\hline Group & Test factor & df & $\begin{array}{c}\text { Mean } \\
\text { square }\end{array}$ & F & sig & $\begin{array}{c}\text { Observed } \\
\text { power }\end{array}$ \\
\hline \multirow{3}{*}{ Cluster } & CCK & 1 & 2566.687 & 110.019 & .000 & 1.000 \\
& SCK & 1 & 1191.826 & 73.259 & .000 & 1.000 \\
& KCS & 1 & 859.480 & 79.116 & .000 & 1.000 \\
\hline
\end{tabular}

When looking at Table 7, we see that there is a significant difference in the CCK, SCK and KCS scores of prospective secondary mathematics teachers justified by a significant Wilk's lambda of $0.55, \mathrm{p}<.001$. There was a statistically significant difference between the covariance matrices of Cluster 1 and Cluster 2 with a significant Box's M value of 23.88, p < .001. The DFA generated only one discriminant function. This could have been due to the fact that only two clusters were being used in the analysis. To check the robustness of the DFA we considered the log determinants of the two clusters. Table 7 shows that the log determinants do not differ greatly, which confirms the robustness of the DFA.

Table 7

Multivariate analysis of prospective secondary mathematics teachers' knowledge of the function concept between clusters

\begin{tabular}{ccccccc}
\hline & \multirow{2}{*}{ Box's M } & \multirow{2}{*}{ Sig } & \multirow{2}{*}{ Wilk's Lambda } & \multirow{2}{*}{ Sig } & \multicolumn{2}{c}{ Log Determinants } \\
\cline { 5 - 7 } & & & & Cluster 1 & Cluster 2 \\
\hline Cluster & 23.880 & .001 & .551 & .000 & 6.026 & 7.334 \\
\hline
\end{tabular}

Table 8 shows the results of the test of equality of cluster mean scores for prospective secondary mathematics teachers' knowledge of the function concept. It can be seen that the Wilk's lambda is statistically significant for all the independent variables $(p<.05)$ using the F-test. Following a rule of thumb which states that the smaller the Wilk's lambda the more important the independent variable to the discriminant function, common content knowledge (CCK) is the most important factor in discriminating between prospective teachers in Cluster 1 and those in Cluster 2.

Table 8

Test of equality of cluster mean scores for prospective secondary mathematics teachers' knowledge of the function concept

\begin{tabular}{cccccc}
\hline & $\begin{array}{c}\text { Wilk's } \\
\text { lambda }\end{array}$ & $\mathrm{F}$ & $\mathrm{df1}$ & $\mathrm{df2}$ & $\mathrm{Sig}$ \\
\hline CCK & .572 & 110.019 & 1 & 147 & .000 \\
SCK & .667 & 73.259 & 1 & 147 & .000 \\
KCS & .650 & 79.116 & 1 & 147 & .000 \\
\hline
\end{tabular}

Finally, Table 9 shows standardized and unstandardized discriminant function coefficients. The purpose for which these coefficients are used is similar to that of beta weights in regression analysis. Standardized coefficients are used to indicate the relative importance of the independent variable in predicting the dependent variable. Thus, the higher the absolute value of the standardized coefficient, the greater the discriminating ability. Just like unstandardized regression coefficients in regression analysis, the unstandardized coefficients in this study were used to construct the prediction equation for the classification of new cases. 
Table 9

Standardized and unstandardized canonical discriminant function coefficients

\begin{tabular}{ccc}
\hline Knowledge domain & Standardized coefficients & $\begin{array}{c}\text { Unstandardized } \\
\text { coefficients }\end{array}$ \\
\hline CCK & .748 & .155 \\
SCK & -.023 & -.006 \\
KCS & .372 & .113 \\
\hline
\end{tabular}

The purpose of this study was to examine prospective secondary mathematics teachers' subject-matter and pedagogical content knowledge of the function concept with particular focus on their CCK, SCK, and KCS, which are part of the MKT framework (Ball et al., 2008). It has been revealed by this study that prospective secondary mathematics teachers had insufficient knowledge of the function concept. This finding is consistent with the findings of other studies (Even, 1993; Karahasan, 2010; Taşdan \& Koyunkaya, 2017).

Although cluster analysis generated two clusters of participants based on their CCK, SCK and KCS characteristics, the overall picture suggests that their knowledge was limited in all the three knowledge domains. The prospective teachers' inability to predict and adequately resolve their students' misconceptions, difficulties and errors had serious implications for their future classrooms. Addressing these knowledge inadequacies while still in university would reduce the chances of transferring the knowledge gap to their learners.

The prospective teachers' low levels of proficiency in their KCS imply that if they do not improve they would face challenges in identifying and adequately resolving secondary school students' misconceptions, difficulties, and errors, leading to serious implications for their future classrooms. In Zambia, the analysis of performance of Grade 12 students in the subjects Mathematics and Additional Mathematics (see Table 10 for global results from year 2017 reported by the Examinations Council of Zambia) show that low knowledge of functions always emerges as one of the main problems behind the poor results obtained as it is necessary to perform well in many other topics like trigonometry or calculus. In fact, graphs of cubic and quadratic functions were noted as being among the challenging topics in the examination procedures and lack of knowledge of functions concepts contributed to some students scoring zero. It can be seen that in the 2017 Grade 12 Mathematics national examinations 1,189 candidates scored zero while the number increased in paper 2 of the same examination with 5, 588 scorings zero. Additional Mathematics 79 and 29 candidates scored zero in paper 1 and paper 2 respectively. With good knowledge of functions, these figures could be reduced or completely eradicated.

Table 10

Results from 2017 National Examinations at Grade 12

\begin{tabular}{ccccc}
\hline Year of Examination & \multicolumn{2}{c}{ Subject } & No. of students who sat & $\begin{array}{c}\text { No. of students who } \\
\text { scored zero }\end{array}$ \\
\hline \multirow{2}{*}{2017} & Mathematics & Paper 1 & 132,530 & 1189 \\
& Additional & Paper 2 & 132,530 & 5588 \\
& Mathematics & Paper 2 & 4,823 & 79 \\
& Maper 1 & 4,823 & 29 \\
\hline
\end{tabular}

As regards participants' CCK and SCK, the results of this study are consistent with the findings of Malambo ( $\underline{2016}$ ). The low mean scores recorded by participants of this study in their CCK and SCK are similar to the findings Malambo (2016) who revealed that pre- 
service teachers had low CCK and SCK of the function concept. Even(1993) also had similar findings in her study.

\section{Conclusion}

Previous studies and the current study have shown that university prospective teachers still face difficulties with the function concept. It is important for institutions that offer teacher education in Zambia to consider research results from local studies like this one to find solutions to problems facing their trainee teachers. There should also be a policy shift from curricula focusing exclusively -or mainly- on subject-matter courses to a situation with an equilibrium of subject-matter content and pedagogical content within the curricula designed for teachers training programs. Participants' insufficient knowledge of content and teaching revealed by this study means that even teachers with good knowledge of mathematical content can do very little to solve secondary school students' misconceptions and errors. There should be more emphasis on KCS in tertiary institutions in Zambia for teachers to teach effectively and accomplish the desired curriculum objectives.

\section{Acknowledgment}

The authors want to express their gratitude to all the participants in this study for their kind and selfless collaboration.

\section{Bibliography}

Aksu, Z., \& Kul, U. (2016). Exploring mathematics teachers' pedagogical content knowledge in the context of knowledge of students. Journal of Education and Practice, 7(30), 3542. Retrieved from www.files.eric.ed.gov/fulltext/EJ1118898.pdf

Aziz, T. A., \& Kurniasih, M. D. (2019). External Representation Flexibility of Domain and Range of Function. Journal on Mathematics Education, 10(1), 143-156. https://doi.org/files.eric.ed.gov/fulltext/EJ1204824.pdf

Aziz, T. A., Pramudiani, P., \& Purnomo, Y. W. (2018). Differences between quadratic equations and functions: Indonesian pre-service secondary mathematics teachers' views. Journal of Physics: Conference Series, 948(1), 012043. https://doi.org/10.1088/1742-6596/948/1/012043

Ball, D. L., Thames, M. H., \& Phelps, G. (2008). Content Knowledge for Teaching: What makes it Special? Journal of Teacher Education, 59(5), 389-407. https://doi.org/10.1177/0022487108324554

Creswell, J. W. (2014). Research design: Qualitative, quantitative and mixed methods approaches. Thousand Oaks, CA: Sage

Even, R. (1990). Subject-matter knowledge for teaching and the case of functions. Education Studies in Mathematics Education, 21(6), 521-544. https://doi.org/10.1007/BF00315943

Even, R. (1993). Subject-matter knowledge and pedagogical content knowledge: Prospective secondary teachers and the function concept. Journal for Research in Mathematics Education, 24(2), 94-116. https://doi.org/10.2307/749215

Hatisaru, V., \& Erbas, A. K. (2017). Mathematical knowledge for teaching the function concept and student learning outcomes. Journal of Science and Mathematics Education, 15(4), 703-722. https://doi.org/10.1007/s10763-015-9707-5

Malambo, P. (2016). Exploring Zambian mathematics student teachers' content knowledge of functions and trigonometry for secondary schools (University of Pretoria). Retrieved 
from www.hdl.handle.net/2263/52943

Malambo, P., Van Putten, S., Botha, J. J., \& Stols, G. H. (2019). Dysfunctional functions: the case of Zambian mathematics education students. Eurasia Journal of Mathematics, Science and Technology Education, 15(1), em 1651. https://doi.org/10.29333/ejmste/99510

McCulloch, A., Lovett, J., \& Edgington, C. (2019). Designing to Provoke Disorienting Dilemmas: Transforming Preservice Teachers' Understanding of Function Using a Vending Machine Applet. Contemporary Issues in Technology and Teacher Education, 19(1), 4-22. Retrieved from https://www.learntechlib.org/primary/p/177835/

Nyikahadzoyi, M. R. (2015). Teachers' knowledge of the concept of a function: A theoretical framework. International Journal of Science and Mathematics Education, 13, 261-283. https://doi.org/10.1007/s10763-013-9486-9

Paoletti, T., Stevens, I. ., Hobson, N. ., Moore, K. ., \& LaForest, K. R. (2018). Inverse function: Pre-service teachers' techniques and meanings. Educational Studies in Mathematics, 97(1), 93-109. https://doi.org/10.1007/s10649-017-9787-y

Ribeiro, A. J., \& da Ponte, J. P. (2019). Professional learning opportunities in a practicebased teacher education programme about the concept of function. Acta Scientiae, 21(2), 49-74. https://doi.org/10.17648/acta.scientiae.v21iss2id5002

Sajka, M. (2003). A secondary school student's understanding of the concept of function-A case study. Educational Studies in Mathematics, 53(3), 229-254. https://doi.org/10.1023/A:1026033415747

Shulman, L. . (1986). Those who understand; Knowledge growth in teaching. Educational Researcher, 15(2), 4-14. Retrieved from www.jstor.org/stable/1175860

Sintema, E.J., Phiri, P.A., \& Marbán, J.M. (2018). Zambian mathematics pre-service secondary teachers' knowledge of the function concept: Theoretical framework and a literature review with implications for Zambia. Journal of Global Research in Education and Social Science, 12(3), 133-147 Retrieved from http://ikprress.org/index.php/JOGRESS/article/view/4367

Steele, M. D., Hillen, A. F., \& Smith, M. S. (2013). Developing mathematical knowledge for teaching in a methods course: the case of function. Journal of Mathematics Teacher Education, 16(6), 451-482. https://doi.org/10.1007/s10857-013-9243-6

Taşdan, B. T. (2019). Mathematics Teachers' Use of Mathematical Descriptions, Explanations and Justifications While Teaching Function Concept: The Case of Samet. Journal of Theoretical Educational Science/KuramsalEğitimbilim Dergisi, 12(4). https://doi.org/10.30831/akukeg.478101

Taşdan, B. T., \& Koyunkaya, M. Y. (2017). Examination of pre-service mathematics teachers' knowledge of teaching function concept. Acta Didactica Napocensia, 4(3), 1-17. Retrieved from www.files.eric.ed.gov/fulltext/EJ1160576.pdf

Thames, M. H., \& Ball, D. L. (2010). What Maths Knowledge Does Teaching Require? Teaching Children Mathematics, 17(4), 220-229. https://doi.org/10.2307/41199946

Ubah, I. J. A., \& Bansilal, S. (2018). Pre-service mathematics teachers' knowledge of mathematics for teaching: quadratic functions. Problems of Education in the 21st Century, 76(6), 847-863. https://doi.org/10.33225/pec/18.76.847

Watson, A., Ayalon, M., \& Lerman, S. (2018). Comparison of students' understanding of functions in classes following English and Israel national curricula. Education Studies in Mathematics, 97(3), 255-272. https://doi.org/10.1007/s10649-017-9798-8

You, Z. (2010). Preservice teachers' knowledge of linear functions within multiple representation modes (Texas A \& $\mathrm{M}$ University). Retrieved from www.core.ac.uk/download/pdf/4277909.pdf 